\title{
Recent progress in melioidosis and glanders
}

\author{
Alfredo G. Torres ${ }^{1 *}$ and Ivo Steinmetz ${ }^{2}$ \\ 1 Department of Microbiology and Immunology, University of Texas Medical Branch, Galveston, TX, USA \\ 2 Friedrich Loeffler Institute of Medical Microbiology, University of Greifswald, Greifswald, Germany \\ *Correspondence: altorres@utmb.edu
}

Burkholderia mallei, the causative agent of glanders, an endemic disease in many parts of the world including the Middle East and Asia, and B. pseudomallei, the etiological agent of melioidosis, an environmental saprophyte endemic in Southeast Asia and Northern Australia, are two pathogens with renewed scientific interest. This is due to their potential to cause severe infections by airborne transmission, non-satisfying treatment options, but also due to their fascinating intracellular life cycle and high virulence in rodents, which makes them most promising model pathogens to study basic infection mechanisms.

This Frontiers Research Topic is focused on the recent progress to understand these two pathogens and their diseases at the molecular level, with special emphasis on bacterial virulence mechanisms in host-pathogen interactions, and the development of therapeutic interventions and vaccines to combat those infections.

In the paper by Allwood et al. (2011), the authors reviewed the pathogenesis of melioidosis in the hallmark of B. pseudomallei's ability to enter, survive, and replicate within mammalian host cells. The mechanisms used by the bacteria to circumvent autophagy and other intracellular defense mechanisms, resulting in bacterial intracellular replication and spread to adjacent cells with the subsequent formation of multi-nucleated giant cells is also discussed.

The review by Lazar Adler et al. (2011) provides and up-todate perspective of the in silico, in vitro, and in vivo studies on the autotransporter proteins of B. pseudomallei and B. mallei. Special emphasis is given to BimA, the best characterized autotransporter of pathogenic Burkholderia and its role as a mediator of actin-based motility; however, the predicted functions of the other autotransporters found in these organisms is also discussed.

Warawa et al. (2011) describe a bioluminescent imaging technique that permits in vivo investigation of pulmonary melioidosis in a murine respiratory disease model. This approach helped the investigators to reveal distinct temporal patterns of bacterial colonization of the mice organs and permitted the evaluation of a capsule mutant, which colonized the upper respiratory tract better than the wild type strain.

Since the liver is a commonly affected organ during melioidosis, the study by Bast et al. (2011), aimed to investigate the anti-B. pseudomallei activity of hepatocytes. The investigators established an in vitro hepatocyte infection model to study host defense mechanisms against $B$. pseudomallei, and observed that the bacteria can invade, escape the vacuole, and replicate within hepatocytes. Further, they determined that IFN $\gamma$ can restrict growth of the pathogen in these cells.
Another area of active investigation focuses in the fact that B. pseudomallei and B. mallei can survive hostile conditions, becoming resilient to many antimicrobial agents, including antibiotics.

In the paper by Rholl et al. (2011), the resistance to $\beta$-lactams, such as ceftazidime, was investigated. Genetic analysis of penA gene, encoding a putative twin arginine translocase (TAT)-secreted $\beta$-lactamase, demonstrated that PenA is secreted via the TAT system and that this $\beta$-lactamase plays a significant role in B. pseudomalleis resistance to these family of antibiotics.

Massey et al. (2011) also took advantage of the bioluminescent imaging technology to study the progression of a B. mallei respiratory infection in the murine model, as well as to establish the efficacy of antibiotic therapy against this pathogen in real-time. This study demonstrated that the $B$. mallei reporter strain maintained similar virulence properties as the wild type strain and allowed visualization of the bacteria in the lungs and through progression to the liver and spleen over the course of infection. Finally, bioluminescence was useful to study efficacy of the antibiotic treatment against murine glanders.

The review by Patel et al. (2011) presents a summary of B. pseudomallei vaccine development efforts, including a summary of the immune responses required for protective immunity, the animal models available for preclinical testing of potential candidates, the different experimental vaccine strategies which have being pursued, and the obstacles and opportunities for eventual registration of a licensed vaccine in humans.

In the case of the B. mallei vaccine efforts, the manuscript by Whitlock et al. (2011) describes the global evaluation of the genome of B. mallei ATCC23344 strain by expression library immunization for gene-encoded protective antigens. The study revealed new putative vaccine candidates, including five candidates that were individually tested and found to confer significant partial protection against a lethal pulmonary infection in a murine model of disease.

Overall, this Special Research Topic, dedicated to study B. mallei and B. pseudomallei pathogenesis and therapeutic approaches, summarizes the progress that has been made over the past few years in this field, and highlights potential opportunities for future research. It is evident that understanding glanders and melioidosis disease requires more investigators to participate because many areas remained to be understood. With the continue threat that represent the use these pathogens as bioweapons and the limited options for antimicrobial treatment, and no vaccines available, further research in this field is critical. 


\section{REFERENCES}

Allwood, E. M., Devenish, R. J., Prescott, M., Adler, B., and Boyce, J. D. (2011). Strategies for intracellular survival of Burkholderia pseudomallei. Front. Microbiol. 2:170. doi: 10.3389/ fmicb.2011.00170

Bast, A., Schmidt, I. H., Brauner, P., Brix, B., Breitbach, K., and Steinmetz, I. (2011). Defense mechanisms of hepatocytes against Burkholderia pseudomallei. Front. Microbiol. 2:277. doi: 10.3389/fmicb.2011.00277

Lazar Adler, N. R., Stevens, J. M., Stevens, M. P., and Galyov, E. E. (2011). Autotransporters and their role in the virulence of Burkholderia pseudomallei and Burkholderia mallei. Front. Microbiol. 2:151. doi: 10.3389/fmicb.2011.00151
Massey, S., Johnston, K., Mott, T. M., Judy, B. M., Kvitko, B. H., Schweizer, H. P., Estes, D. M., and Torres, A. G. (2011). In vivo bioluminescence imaging of Burkholderia mallei respiratory infection and treatment in the mouse model. Front. Microbiol. 2:174. doi: 10.3389/fmicb.2011.00174

Patel, N., Conejero, L., De Reynal, M., Easton, A., Bancroft, G. J., and Titball, R.W. (2011). Development of vaccines against Burkholderia pseudomallei. Front. Microbiol. 2:198. doi: 10.3389/ fmicb.2011.00198

Rholl,D.A.,Papp-Wallace, K. M., Tomaras, A. P., Vasil, M. L., Bonomo, R. A., and Schweizer, H. P. (2011). Molecular investigations of PenA-mediated $\beta$-lactam resistance in Burkholderia pseudomallei. Front. Microbiol. 2:139. doi: $10.3389 /$ fmicb.2011.00139

Warawa, J. M., Long, D., Rosenke, R., Gardner, D., and Gherardini, F. C. (2011). Bioluminescent diagnostic imaging to characterize altered respiratory tract colonization by the Burkholderia pseudomallei capsule mutant. Front. Microbiol. 2:133. doi: 10.3389/fmicb.2011.00133

Whitlock, G. C., Robida, M. D., Judy, B. M., Qazi, O., Brown, K. A., Deeraksa, A., Taylor, K., Massey, S., Loskutov, A., Borovkov, A. Y., Brown, K., Cano, J. A., Torres, A. G., Estes, D. M., and Sykes, K.F. (2011). Protective antigens against glanders identified by expression library immunization. Front. Microbiol 2:227. doi: 10.3389/fmicb.2011.00227
Received: 29 March 2012; accepted: 29 March 2012; published online: 19 April 2012.

Citation: Torres AG and Steinmetz I (2012)

Recent progress in melioidosis and glanders. Front. Microbio. 3:149. doi: 10.3389/ fmicb.2012.00149

This article was submitted to Frontiers in Cellular and Infection Microbiologyclosed section, a specialty of Frontiers in Microbiology.

Copyright $\odot 2012$ Torres and Steinmetz. This is an open-access article distributed under the terms of the Creative Commons Attribution Non Commercial License, which permits non-commercial use, distribution, and reproduction in other forums, provided the original authors and source are credited. 